\title{
Aging, obesity, and post-therapy cognitive recovery in breast cancer survivors
}

\author{
Zhezhou Huang ${ }^{1}$, Ying Zheng ${ }^{2}$, Pingping $\mathrm{Bao}^{3}$, Hui Cai ${ }^{4}$, Zhen Hong5, Ding Ding ${ }^{5}$, \\ James Jackson ${ }^{6}$, Xiao-Ou Shu ${ }^{4}$ and Qi Dai ${ }^{4}$ \\ ${ }^{1}$ Department of Elderly Health, Division of Noncommunicable Disease and Injury, Shanghai Municipal Center for Disease \\ Control and Prevention, Shanghai, China \\ 2 Department of Cancer Control and Prevention, Division of Noncommunicable Disease and Injury, Shanghai Municipal \\ Center for Disease Control and Prevention, Shanghai, China \\ 3 Department of Noncommunicable Disease Surveillance, Division of Noncommunicable Disease and Injury, Shanghai \\ Municipal Center for Disease Control and Prevention, Shanghai, China \\ ${ }^{4}$ Department of Medicine, Division of Epidemiology, Vanderbilt University School of Medicine, Nashville, Tennessee, USA \\ ${ }^{5}$ Department of Neurology, Huashan Hospital, Fudan University, Shanghai, China \\ ${ }^{6}$ Division of Allergy, Pulmonary, and Critical Care Medicine, Department of Medicine, Vanderbilt University School of Medicine, \\ Nashville, Tennessee, USA
}

Correspondence to: Ying Zheng, email: zhengying@scdc.sh.cn

Keywords: breast cancer survivor, cognitive, age, obesity, physical activity

Received: June 21,2016 Accepted: October 03, $2016 \quad$ Published: October 11, 2016

\section{ABSTRACT}

Therapy-induced cognitive impairment is prevalent and long-lasting in cancer survivors, but factors affecting post-therapy cognitive recovery are unclear. We conducted this study to evaluate the associations of age, body mass index (BMI), waist-to-hip ratio (WHR), and physical activity (PA) with post-therapy cognitive changes in a population-based breast cancer (BC) survivor cohort. We collected information on PA, weight, height, waist and hip circumferences of 1286 BC survivors aged 20-75. We assessed their cognitive functions, including immediate memory, delayed memory, verbal fluency, and attention, at 18 and 36 months after cancer diagnosis. Linear regression models were used to examine the associations of age, BMI, WHR and PA with mean changes in cognitive scores from 18- to 36-month follow-up interview. We found that the post-therapy cognitive changes differed by age and obesity status. Verbal fluency and attention improved in younger patients aged $<60$ and non-abdominally obese patients, but deteriorated in older patients aged $\geq 60$ (i.e. verbal fluency and attention) and abdominally obese patients (i.e. verbal fluency). Memory improved in all patients, with a smaller improvement in obese patients compared with normal-weight patients. No significant association was found between PA and post-therapy cognitive change. Due to the novelty of our findings and the limitations of our study, further research, including intervention trials, is warranted to confirm the causal relationship between obesity and cognitive impairments.

\section{INTRODUCTION}

Clinically significant cognitive impairment caused by cancer adjuvant therapy, particularly chemotherapy, is highly prevalent in cancer survivors $[1,2]$. Previous prospective studies, including our own, have shown that the cognitive impairment starts to dissipate after the cessation of chemotherapy $[3,4]$. However, it persists in some cancer survivors for fully 20 years [5]. Thus, identification of modifiable factors affecting the recovery from cognitive impairment in cancer survivors will benefit this rapidly growing population.

Aging is a well-established risk factor for cognitive decline in the healthy elderly [6]. Previous studies have also linked energy balance-related factors, such as obesity and physical activity (PA), to aging-related 
Table 1: Comparisons of characteristics at 18-month follow-up interview between participants eligible for the Cognition Sub-study and those who completed the study

\begin{tabular}{|c|c|c|c|c|c|}
\hline & $\begin{array}{l}\text { Participants eligible } \\
\text { for the Cognition } \\
\text { Sub-study } \\
(n=1385)\end{array}$ & $\begin{array}{c}\text { Participants } \\
\text { completed the first } \\
\text { cognitive assessment } \\
(n=1286)\end{array}$ & $P^{a}$ & $\begin{array}{l}\text { Participants } \\
\text { completed the } \\
\text { second cognitive } \\
\text { assessment } \\
(n=1047)\end{array}$ & $P^{\mathbf{b}}$ \\
\hline & Mean (SD) / $n(\%)^{\mathrm{c}}$ & Mean (SD) / $n(\%)^{\mathrm{c}}$ & & Mean (SD) $/ n(\%)^{\mathrm{c}}$ & \\
\hline Age at diagnosis (years) & $53.4(9.7)$ & $53.4(9.7)$ & 0.81 & $53.5(9.6)$ & 0.65 \\
\hline $\begin{array}{l}\text { Age at 18-month follow-up interview } \\
\text { (years) }\end{array}$ & $55.0(9.7)$ & $54.9(9.7)$ & 0.81 & $55.1(9.6)$ & 0.66 \\
\hline Monthly income (¥/month/capita) & & & 0.97 & & 0.97 \\
\hline$<1000$ & $651(47.0)$ & $600(46.7)$ & & $494(47.2)$ & \\
\hline $1000-2000$ & $532(38.4)$ & $500(38.9)$ & & $402(38.4)$ & \\
\hline$>2000$ & $202(14.6)$ & $186(14.4)$ & & $151(14.4)$ & \\
\hline Educational attainment & & & 0.78 & & 0.96 \\
\hline Elementary school or below & $625(45.1)$ & $564(43.8)$ & & $464(44.3)$ & \\
\hline Middle or high school & $527(38.1)$ & $505(39.3)$ & & $410(39.2)$ & \\
\hline College or above & $233(16.8)$ & $217(16.9)$ & & $173(16.5)$ & \\
\hline Postmenopausal & $1031(74.4)$ & $956(74.3)$ & 0.95 & $786(75.1)$ & 0.69 \\
\hline Depression score & & & 0.97 & & 0.98 \\
\hline 0 & $427(40.4)$ & $410(40.9)$ & & $371(40.9)$ & \\
\hline 1 & $378(35.7)$ & $354(35.3)$ & & $323(35.6)$ & \\
\hline$\geqslant 2$ & $253(23.9)$ & $239(23.8)$ & & $213(23.5)$ & \\
\hline Stage of cancer (TNM classification) & & & 1.00 & & 0.98 \\
\hline I & $520(37.6)$ & $488(38.0)$ & & $403(38.5)$ & \\
\hline IIA & $479(34.6)$ & $440(34.2)$ & & $363(34.7)$ & \\
\hline IIB & $190(13.7)$ & $180(14.0)$ & & $146(13.9)$ & \\
\hline III and above & $129(9.3)$ & $116(9.0)$ & & $87(8.3)$ & \\
\hline Unknown & $67(4.8)$ & $62(4.8)$ & & $48(4.6)$ & \\
\hline Ever had surgery & $1379(99.6)$ & $1280(99.5)$ & 0.90 & $1042(99.5)$ & 0.97 \\
\hline Ever undergone radiotherapy & $460(33.2)$ & $428(33.3)$ & 0.97 & $345(33.0)$ & 0.87 \\
\hline Ever undergone chemotherapy & $1283(92.6)$ & $1194(92.9)$ & 0.83 & $975(93.1)$ & 0.79 \\
\hline Ever used tomoxifen & $643(46.5)$ & $595(46.3)$ & 0.94 & $497(47.5)$ & 0.57 \\
\hline $\begin{array}{l}\text { Time since the cessation of cancer therapy } \\
\text { at } 18 \text {-month follow-up interview (months) }\end{array}$ & $14.1(1.9)$ & $14.0(1.9)$ & 0.81 & $14.0(1.9)$ & 0.67 \\
\hline $\begin{array}{l}\text { Time since the cessation of cancer therapy } \\
\text { at 36-month follow-up interview (months) }\end{array}$ & $32.5(1.9)$ & $32.5(1.9)$ & 0.84 & $32.5(1.9)$ & 0.57 \\
\hline $\begin{array}{l}\text { Breast cancer recurrence or diagnosis of } \\
\text { other malignancies after diagnosis of } \\
\text { breast cancer }\end{array}$ & $215(16.3)$ & $194(15.8)$ & 0.73 & $146(14.6)$ & 0.43 \\
\hline \multicolumn{6}{|l|}{ Comorbidities } \\
\hline Cardiovascular disease & $302(25.4)$ & $284(25.3)$ & 0.92 & $263(25.5)$ & 0.91 \\
\hline Hypertension & 339 (28.4) & $320(28.2)$ & 0.95 & $291(28.0)$ & 0.89 \\
\hline Diabetes mellitus & $143(12.1)$ & $138(12.3)$ & 0.86 & $127(12.4)$ & 0.96 \\
\hline
\end{tabular}




\begin{tabular}{|c|c|c|c|c|c|}
\hline Chronic liver disease & $476(39.7)$ & $448(39.5)$ & 0.91 & $407(39.1)$ & 0.87 \\
\hline Chronic gastric disease & $227(19.0)$ & $217(19.1)$ & 0.91 & $206(20.0)$ & 0.68 \\
\hline Urinary system disease & $126(10.5)$ & $118(10.4)$ & 0.92 & $108(10.4)$ & 0.99 \\
\hline Chronic lung disease & $96(8.0)$ & $93(8.2)$ & 0.87 & $87(8.4)$ & 0.88 \\
\hline BMI $\left(\mathrm{kg} / \mathrm{m}^{2}\right)$ & & & 1.00 & & 0.97 \\
\hline Underweight $(<18.5)$ & $27(2.0)$ & $26(2.0)$ & & $20(1.9)$ & \\
\hline Normal (18.5-23.9) & $653(47.1)$ & $608(47.3)$ & & $488(46.6)$ & \\
\hline Overweight (24.0-27.9) & $516(37.3)$ & $480(37.3)$ & & $401(38.3)$ & \\
\hline Obese $(\geqslant 28.0)$ & $189(13.6)$ & $172(13.4)$ & & $138(13.2)$ & \\
\hline WHR & & & 0.96 & & 0.84 \\
\hline Normal $(<0.80)$ & $297(21.4)$ & $277(21.5)$ & & $236(22.6)$ & \\
\hline $0.80-0.84$ & $430(31.1)$ & $405(31.5)$ & & $328(31.3)$ & \\
\hline Abdominally obese $(\geqslant 0.85)$ & $658(47.5)$ & $604(47.0)$ & & $483(46.1)$ & \\
\hline PA (METs-hours/week) & & & 0.88 & & 0.78 \\
\hline Light-intensity $(<8.3$ ) & $660(47.7)$ & $602(46.8)$ & & $477(45.6)$ & \\
\hline Moderate-intensity (8.3-16.5) & $306(22.1)$ & $284(22.1)$ & & $231(22.0)$ & \\
\hline Vigorous-intensity $(\geqslant 16.6)$ & $419(30.2)$ & $400(31.1)$ & & $339(32.4)$ & \\
\hline
\end{tabular}

${ }^{a}$ Compared between participants eligible for the Cognition Sub-study and those who completed the first cognitive assessment at 18-month follow-up interview

Compared between participants who completed the first and second cognitive assessments at 18- and 36-month follow-up interviews, respectively

${ }^{\mathrm{c}}$ Mean (SD) for continuous variables or $\mathrm{n}(\%)$ for categorical variables

Abbreviations: SD, standard deviation

cognitive decline [7, 8]. Physiological consequences of obesity such as chronic inflammation, hypertension, hyperlipidemia, insulin resistance and subsequent diabetes, have deleterious effects on innate immunity, which in turn directly harm the central nervous system [9]. PA, a factor interrelated with body fat, may help maintain cognitive function in elders, through enhancing cardiovascular health, helping decrease brain dysfunction and neurodegeneration caused by inflammation, lowering amyloid loading, increasing levels of neurotransmitters and insulin-like growth factor I, etc [10].

However, the associations between energy balancerelated factors and post-therapy cognitive recovery in cancer survivors have not been investigated. We hypothesized that energy balance-related factors affect the post-therapy cognitive recovery in cancer survivors. Hence, we conducted this study to longitudinally investigate the associations of age and energy balancerelated factors, including body mass index (BMI), waistto-hip ratio (WHR, i.e. a measure of visceral adiposity) and PA, with post-therapy cognitive recovery in a large cohort of breast cancer (BC) survivors.

\section{RESULTS}

As shown in Table 1, we found no significant differences in demographic characteristics, menopausal status, depression, cancer diagnosis, progression and treatments, time since the cessation of cancer therapy, BMI, WHR and PA between participants who were eligible for the Cognition Sub-study and who completed the first cognitive assessment, nor between participants who completed the first and second cognitive assessments. Participants included in the Cognition Sub-study had a mean age of 54.9 at the 18-month follow-up interview. Among them, $37.3 \%$ were overweight $(24.0 \leq \mathrm{BMI}$ $<28.0$ ) and $13.4 \%$ were obese (BMI $\geq 28.0) ; 47.0 \%$ were abdominally obese (WHR $\geq 0.85$ ); and $46.8 \%$ were physically inactive (PA intensity $<8.3$ METshours/week). The majority of our participants (92.9\%) underwent chemotherapy. The interval from the cessation of cancer therapy to the 18- and 36-month follow-up interviews was 14.0 and 32.5 months, respectively. The main comorbidities reported by our participants included chronic liver disease (39.1\%), hypertension (28.0\%), cardiovascular disease $(25.5 \%)$, chronic gastric disease (20.0\%), and diabetes mellitus (12.4\%).

Table 2 shows the associations of age, BMI, WHR and PA with mean change (MC) in cognitive scores from the 18- to 36-month follow-up interview. Age was significantly associated with mean changes in verbal fluency $\left(P^{1}=0.02\right)$ and attention $\left(P^{1}<0.001\right)$. Noticeably, verbal fluency improved in younger patients (MC (SE): $1.1(0.5)$ and $0.9(0.3)$ for patients aged $<50$ and 50-59, respectively), but deteriorated in older patients aged $\geq 60$ (MC (SE): -0.4 (0.4)). The difference in mean changes in 
Table 2: Associations of age, BMI, WHR and PA with changes in cognitive scores from 18- to 36-month follow-up interview $(n=1047)$

\begin{tabular}{|c|c|c|c|c|c|c|c|c|c|c|c|c|c|c|c|c|c|c|c|c|c|c|c|c|}
\hline & \multicolumn{6}{|c|}{ Immediate memory score } & \multicolumn{6}{|c|}{ Delayed memory score } & \multicolumn{6}{|c|}{ Verbal fluency score } & \multicolumn{6}{|c|}{ Attention score } \\
\hline & \multicolumn{2}{|c|}{ Absolute value } & \multicolumn{3}{|c|}{ Relative value } & \multirow[b]{2}{*}{$\begin{array}{c}\text { Cohen's } \\
d\end{array}$} & \multicolumn{2}{|c|}{ Absolute value } & \multicolumn{3}{|c|}{ Relative value } & \multirow{2}{*}{$\begin{array}{c}\text { Cohen's } \\
d \quad\end{array}$} & \multicolumn{2}{|c|}{ Absolute value } & \multicolumn{3}{|c|}{ Relative value } & \multirow{2}{*}{$\begin{array}{c}\text { Cohen's } \\
\quad d\end{array}$} & \multicolumn{2}{|c|}{ Absolute value } & \multicolumn{3}{|c|}{ Relative value } & \multirow{2}{*}{$\begin{array}{c}\text { Cohen's } \\
d\end{array}$} \\
\hline & MC (SE) & $P^{1}$ & Diff (SE) & $P^{2}$ & $P^{3}$ & & $\begin{array}{l}\text { MC } \\
\text { (SE) }\end{array}$ & $P^{1}$ & Diff (SE) & $P^{2}$ & $P^{3}$ & & MC (SE) & $P^{1}$ & Diff (SE) & $P^{2}$ & $P^{3}$ & & $\begin{array}{l}\text { MC } \\
\text { (SE) }\end{array}$ & $P^{1}$ & Diff (SE) & $P^{2}$ & $P^{3}$ & \\
\hline $\begin{array}{l}\text { Age at 36-month follow-up interview } \\
\text { (years) }\end{array}$ & & 0.42 & & & & & & 0.08 & & & & & & 0.02 & & & & & & $<0.001$ & & & & \\
\hline$<50$ & $1.3(0.3)$ & & $-0.2(0.3)$ & 0.64 & 1.00 & 0.2 & $1.5(0.3)$ & & $-0.3(0.3)$ & 0.31 & 0.93 & 0.3 & $1.1(0.5)$ & & $0.2(0.6)$ & 0.81 & 1.00 & 0.1 & $2.6(0.8)$ & & $-0.8(1.0)$ & 0.44 & 1.00 & 0.1 \\
\hline $50-59$ & $1.4(0.2)$ & & Refe & rence & & 0.3 & $1.8(0.2)$ & & Refer & rence & & 0.4 & $0.9(0.3)$ & & & erence & & 0.1 & $3.4(0.5)$ & & & eference & & 0.19 \\
\hline$\geqslant 60$ & $1.1(0.2)$ & & $-0.3(0.3)$ & 0.19 & 0.58 & 0.2 & $1.2(0.2)$ & & $-0.6(0.3)$ & 0.03 & 0.08 & 0.3 & $-0.4(0.4)$ & & $-1.3(0.5)$ & 0.01 & 0.03 & -0.04 & $\begin{array}{l}-2.2 \\
(0.7)\end{array}$ & & $-5.6(0.9)$ & $<0.001$ & $<0.001$ & -0.1 \\
\hline BMI $\left(\mathbf{k g} / \mathbf{m}^{2}\right)^{b}$ & & 0.18 & & & & & & 0.03 & & & & & & 0.41 & & & & & & 0.49 & & & & \\
\hline Underweight $(<18.5)$ & $1.5(0.8)$ & & $0.1(0.8)$ & 0.90 & 1.00 & 0.4 & $0.6(0.8)$ & & $-1.1(0.8)$ & 0.15 & 0.93 & 0.1 & $1.2(1.4)$ & & $0.7(1.5)$ & 0.64 & 1.00 & 0.2 & $3.3(2.4)$ & & $1.5(2.5)$ & 0.55 & 1.00 & 0.2 \\
\hline Normal (18.5-23.9) & $1.4(0.2)$ & & Refe & rence & & 0.3 & $1.7(0.2)$ & & Refer & rence & & 0.4 & $0.5(0.3)$ & & & erence & & 0.1 & $1.9(0.5)$ & & & eference & & 0.1 \\
\hline Overweight (24.0-27.9) & $1.3(0.2)$ & & $-0.2(0.2)$ & 0.50 & 1.00 & 0.3 & $1.7(0.2)$ & & $0.04(0.2)$ & 0.85 & 1.00 & 0.4 & $0.9(0.3)$ & & $0.4(0.4)$ & 0.39 & 1.00 & 0.1 & $0.9(0.6)$ & & $-0.9(0.7)$ & 0.23 & 1.00 & 0.1 \\
\hline Obese $(\geqslant 28.0)$ & $0.7(0.3)$ & & $-0.8(0.3)$ & 0.03 & 0.17 & 0.2 & $0.8(0.3)$ & & $-0.9(0.4)$ & 0.01 & 0.07 & 0.2 & $-0.2(0.6)$ & & $-0.7(0.6)$ & 0.30 & 1.00 & -0.02 & $0.8(1.0)$ & & $-1.0(1.1)$ & 0.35 & 1.00 & 0.0 \\
\hline WHR $^{b}$ & & 0.13 & & & & & & 0.71 & & & & & & H\#\#\# & & & & & & 0.68 & & & & \\
\hline Normal $(<0.80)$ & $0.9(0.2)$ & & Refe & rence & & 0.2 & $1.4(0.2)$ & & Refer & rence & & 0.3 & $1.4(0.4)$ & & & Erence & & 0.2 & $1.1(0.7)$ & & & eference & & 0.1 \\
\hline $0.80-0.84$ & $1.5(0.2)$ & & $0.6(0.3)$ & \#\#\# & 0.14 & 0.4 & $1.6(0.2)$ & & $0.2(0.3)$ & 0.43 & 1.00 & 0.4 & $1.1(0.4)$ & & $-0.3(0.5)$ & 0.64 & 1.00 & 0.1 & $1.8(0.6)$ & & $0.7(0.9)$ & 0.43 & 1.00 & 0.1 \\
\hline Abdominally obese $(\geqslant 0.85)$ & $1.3(0.2)$ & & $0.4(0.3)$ & 0.13 & 0.39 & 0.3 & $1.6(0.2)$ & & $0.2(0.3)$ & 0.49 & 1.00 & 0.4 & $-0.2(0.3)$ & & $-1.6(0.5)$ & 0.002 & \#\# & -0.03 & $1.3(0.5)$ & & $0.2(0.9)$ & 0.86 & 1.00 & 0.1 \\
\hline PA (METs-hours/week) & & 0.14 & & & & & & 0.27 & & & & & & 0.10 & & & & & & 0.48 & & & & \\
\hline Light-intensity (<8.3) & $1.1(0.2)$ & & $-0.4(0.3)$ & 0.13 & 0.39 & 0.2 & $1.4(0.2)$ & & $-0.3(0.3)$ & 0.25 & 0.75 & 0.3 & $0.3(0.3)$ & & $-1.0(0.5)$ & 0.046 & 0.14 & 0.04 & $1.1(0.5)$ & & $\begin{array}{c}-0.05 \\
(0.9)\end{array}$ & 0.96 & 1.00 & 0.1 \\
\hline Moderate-intensity $(8.3-16.5)$ & $1.5(0.2)$ & & Refe & rence & & 0.3 & $1.7(0.2)$ & & Refer & rence & & 0.4 & $1.4(0.4)$ & & & erence & & 0.2 & $1.1(0.7)$ & & & eference & & 0.1 \\
\hline Vigorous-intensity $(\geqslant 16.6)$ & $1.5(0.2)$ & & $0.002(0.3)$ & 0.99 & 1.00 & 0.4 & $1.7(0.2)$ & & $0.04(0.3)$ & 0.89 & 1.00 & 0.4 & $0.4(0.3)$ & & $-1.0(0.6)$ & 0.07 & 0.20 & 0.05 & $2.0(0.6)$ & & $0.8(0.9)$ & 0.37 & 1.00 & 0.1 \\
\hline
\end{tabular}

\begin{abstract}
${ }^{a}$ Adjusted for cognitive scores at 18-month follow-up interview, educational attainment, income, menopausal status at 36-month follow-up interview, depression score, stage of cancer, breast cancer recurrence or diagnosis of other malignancies before 36-month follow-up interview, cancer treatments (including surgery, radiotherapy, chemotherapy and tamoxifen use), and time since the cessation of cancer therapy at 36-month follow-up interview.

${ }^{\mathrm{b}}$ Addtionally adjusted for age at 36-month follow-up interview

${ }^{1} \mathrm{P}$-value for the overall model significance

${ }^{2} \mathrm{P}$-value for the difference in mean changes in cognitive scores from 18- to 36-month follow-up interview between this

group and the reference group and the reference group after correcting for multiple comparisons using Bonferroni correction.

Abbreviations: MC, mean change in cognitive scores from 18- to 36-month follow-up interview for patients in different groups of age, BMI, WHR and PA intensity; SE, standard error; Diff, difference in mean changes in cognitive score from 18- to 36-month follow-up interview between this group and the reference group
\end{abstract}

verbal fluency between patients aged 50-59 and $\geq 60$ was significant (Diff (SE): $-1.3(0.5), P^{2}=0.01$ ), and it remained significant after being corrected for multiple comparisons $\left(P^{3}=0.03\right)$. Similarly, attention also improved in younger patients (MC (SE): $2.6(0.8)$ and $3.4(0.5)$ for patients aged $<50$ and $50-59$, respectively), but deteriorated in older patients aged $\geq 60$ (MC (SE): $-2.2(0.7)$ ). The difference in mean changes in attention between patients aged 5059 and $\geq 60$ was significant (Diff (SE): $-5.6(0.9), P^{2}<$ 0.001 ), and it remained significant after being corrected for multiple comparisons $\left(P^{3}<0.001\right)$. However, Cohen's $d$ values for mean changes in verbal fluency and attention related to age were not clinically significant (both $|d|<$ $0.2)$. The association between age and delayed memory was marginally significant $\left(P^{\mathrm{l}}=0.08\right)$. Although delayed memory improved across all age groups (all $\mathrm{MC}>0$ ), compared with patients aged 50-59, older patients aged $\geq 60$ had a smaller improvement (Diff (SE): -0.6 (0.3), $P^{2}$ $=0.03$ ). However, this difference was only of borderline significance after being corrected for multiple comparisons $\left(P^{3}=0.08\right)$. Overall, BMI was significantly associated with mean change in delayed memory $\left(P^{1}=0.03\right)$. Although delayed memory improved across all BMI groups (all $\mathrm{MC}>0$ ), compared with normal-weight patients, obese patients (BMI $\geq 28.0$ ) had a smaller improvement (Diff (SE): $\left.-0.9(0.4), P^{2}=0.01\right)$. However, this difference was only of borderline significance after being corrected for multiple comparisons $\left(P^{3}=0.07\right)$. Cohen's $d$ was 0.4 for the improvement in delayed memory among normal-weight patients, indicating a small to moderate clinical significance. WHR was significantly associated with mean change in verbal fluency $\left(P^{1}=0.002\right)$. Verbal fluency improved in non-abdominally obese patients (MC (SE): $1.4(0.4)$ and $1.1(0.4)$ for patients with a WHR ranged $<0.80$ and $0.80-0.84$, respectively), but slightly declined in abdominally obese patients (MC (SE): -0.2 $(0.3))$. The difference in mean changes in verbal fluency between patients with a normal WHR and abdominally obese patients was significant (Diff (SE): $-1.6(0.5), P^{2}=$ $0.002)$, and it remained significant after being corrected for multiple comparisons $\left(P^{3}=0.006\right)$. Cohen's $d$ was 0.2 for the improvement in verbal fluency among patients with a normal WHR, indicating a borderline small clinical significance. Finally, PA was not significantly associated with mean changes in any cognitive domains (all $P^{1}>0.05$ ). Additional interaction analyses examining the interaction between PA and BMI or WHR indicated non-significant interaction effects between PA and BMI or WHR (both $P>0.05$, data not shown). In sensitivity analyses of the patients who underwent chemotherapy $(n$ $=1,194$, data not shown), the difference in mean changes in delayed memory between obese patients and normalweight patients remained significant after being corrected for multiple comparisons $\left(P^{3}=0.03\right)$. No substantial 
Table 3: Associations of age, BMI, WHR and PA with cognitive scores at 18-month follow-up interview (n=1286)

\begin{tabular}{|c|c|c|c|c|c|c|c|c|c|c|c|c|c|c|c|c|c|c|c|c|}
\hline & \multicolumn{5}{|c|}{ Immediate memory score } & \multicolumn{5}{|c|}{ Delayed memory score } & \multicolumn{5}{|c|}{ Verbal fluency score } & \multicolumn{5}{|c|}{ Attention score } \\
\hline & \multicolumn{2}{|c|}{ Absolute value } & \multicolumn{3}{|c|}{ Relative value } & \multicolumn{2}{|c|}{ Absolute value } & \multicolumn{3}{|c|}{ Relative value } & \multicolumn{2}{|c|}{ Absolute value } & \multicolumn{3}{|c|}{ Relative value } & \multicolumn{2}{|c|}{ Absolute value } & \multicolumn{3}{|c|}{ Relative value } \\
\hline & Mean (SE) & $P^{1}$ & Diff (SE) & $P^{2}$ & $P^{3}$ & Mean (SE) & $P^{1}$ & Diff (SE) & $P^{2}$ & $P^{3}$ & Mean (SE) & $P^{1}$ & Diff (SE) & $P^{2}$ & $P^{3}$ & Mean (SE) & $P^{1}$ & Diff (SE) & $P^{2}$ & $P^{3}$ \\
\hline $\begin{array}{l}\text { Age at 18-month follow-up interview } \\
\text { (years) }{ }^{\mathrm{a}}\end{array}$ & & 0.002 & & & & & 0.003 & & & & & $<0.001$ & & & & & $<0.001$ & & & \\
\hline$<50$ & $9.9(0.3)$ & & $-1.0(0.4)$ & 0.02 & 0.0498 & $9.1(0.3)$ & & $-0.9(0.4)$ & 0.03 & 0.08 & $42.1(0.5)$ & & $-0.9(0.7)$ & 0.24 & 0.71 & $80.6(1.1)$ & & $-1.3(1.6)$ & 0.42 & 1.00 \\
\hline $50-59$ & $10.8(0.2)$ & & & erence & & $10.0(0.2)$ & & & ference & & $43.0(0.4)$ & & & ference & & $81.9(0.9)$ & & & eference & \\
\hline$\geqslant 60$ & $9.7(0.3)$ & & $-1.2(0.4)$ & 0.001 & 0.004 & $8.9(0.3)$ & & $-1.1(0.4)$ & 0.002 & 0.006 & $40.2(0.5)$ & & $-2.8(0.7)$ & $<0.001$ & $<0.001$ & $65.5(1.1)$ & & $\begin{array}{l}-16.3 \\
(1.4)\end{array}$ & $<0.001$ & $<0.001$ \\
\hline BMI $\left(\mathrm{kg} / \mathrm{m}^{2}\right)^{\mathrm{b}}$ & & 0.08 & & & & & 0.04 & & & & & 0.23 & & & & & $<0.001$ & & & \\
\hline Underweight $(<18.5)$ & $10.2(1.1)$ & & $-0.3(1.1)$ & 0.78 & 1.00 & $10.1(1.0)$ & & $0.3(1.1)$ & 0.74 & 1.00 & $40.9(1.9)$ & & $-1.5(1.9)$ & 0.45 & 1.00 & $80.8(4.0)$ & & $1.9(4.1)$ & 0.64 & 1.00 \\
\hline Normal (18.5-23.9) & $10.5(0.2)$ & & & erence & & $9.8(0.2)$ & & & ference & & $42.4(0.4)$ & & & ference & & $78.9(0.8)$ & & & eference & \\
\hline Overweight (24.0-27.9) & $10.1(0.2)$ & & $-0.4(0.3)$ & 0.17 & 0.99 & $9.2(0.2)$ & & $-0.5(0.3)$ & 0.07 & 0.42 & $41.8(0.4)$ & & $-0.6(0.5)$ & 0.30 & 1.00 & $76.3(0.9)$ & & $-2.6(1.2)$ & 0.03 & 0.15 \\
\hline Obese $(\geqslant 28.0)$ & $9.4(0.4)$ & & $-1.1(0.4)$ & 0.01 & 0.07 & $8.6(0.4)$ & & $-1.1(0.4)$ & 0.010 & 0.06 & $40.9(0.7)$ & & $-1.5(0.8)$ & 0.05 & 0.32 & $71.8(1.5)$ & & $-7.1(1.7)$ & $<0.001$ & $<0.001$ \\
\hline WHR $^{\mathrm{b}}$ & & 0.002 & & & & & 0.002 & & & & & 0.55 & & & & & 0.003 & & & \\
\hline Normal $(<0.80)$ & $10.7(0.3)$ & & & crence & & $9.9(0.3)$ & & & ference & & $41.5(0.5)$ & & & ference & & $78.9(1.1)$ & & & eference & \\
\hline $0.80-0.84$ & $10.6(0.2)$ & & $-0.04(0.4)$ & 0.92 & 1.00 & $9.8(0.2)$ & & $-0.1(0.4)$ & 0.85 & 1.00 & $42.3(0.4)$ & & $0.7(0.7)$ & 0.27 & 0.81 & $78.7(0.9)$ & & $-0.2(1.4)$ & 0.89 & 1.00 \\
\hline Abdominally obese $(\geqslant 0.85)$ & $9.6(0.2)$ & & $-1.0(0.4)$ & 0.004 & 0.01 & $8.9(0.2)$ & & $-1.0(0.4)$ & 0.004 & 0.01 & $42.0(0.4)$ & & $0.4(0.7)$ & 0.51 & 1.00 & $75.0(0.8)$ & & $-3.8(1.4)$ & 0.006 & 0.02 \\
\hline PA (METs-hours/week) & & 0.74 & & & & & 0.41 & & & & & 0.09 & & & & & 0.16 & & & \\
\hline Light-intensity $(<8.3)$ & $10.1(0.2)$ & & $-0.3(0.4)$ & 0.44 & 1.00 & $9.3(0.2)$ & & $-0.5(0.4)$ & 0.18 & 0.55 & $41.5(0.4)$ & & $-0.5(0.6)$ & 0.47 & 1.00 & $76.3(0.8)$ & & $-2.6(1.4)$ & 0.06 & 0.17 \\
\hline Moderate-intensity (8.3-16.5) & $10.4(0.3)$ & & & erence & & $9.7(0.3)$ & & & ference & & $41.9(0.5)$ & & & ference & & $78.9(1.1)$ & & & eference & \\
\hline Vigorous-intensity $(\geqslant 16.6)$ & $10.2(0.2)$ & & $-0.2(0.4)$ & 0.56 & 1.00 & $9.4(0.2)$ & & $-0.3(0.4)$ & 0.37 & 1.00 & $42.7(0.4)$ & & $0.8(0.7)$ & 0.24 & 0.73 & $76.8(0.9)$ & & $-2.1(1.4)$ & 0.15 & 0.46 \\
\hline
\end{tabular}

${ }^{a}$ Adjusted for educational attainment, income, menopausal status at 18-month follow-up interview, depression score, stage of cancer, breast cancer recurrence or diagnosis of other malignancies before 18-month follow-up interview, cancer treatments (including surgery, radiotherapy, chemotherapy and tamoxifen use), and time since the cessation of cancer therapy at 18-month follow-up interview.

${ }^{\mathrm{b}}$ Addtionally adjusted for age at 18-month follow-up interview

${ }^{1} \mathrm{P}$-value for the overall model significance

${ }^{2} \mathrm{P}$-value for the difference in mean cognitive scores at 18-month follow-up interview between this group and the reference group group after correcting for multiple comparisons using Bonferroni correction

Abbreviations: Mean, mean cognitive score at 18-month follow-up interview for patients in different groups of age, BMI, WHR and PA intensity; SE, standard error; Diff, difference in mean cognitive scores at 18-month follow-up interview between this group and the reference group

difference was found after additional adjustment for comorbidities (data not shown).

Table 3 presents the associations of age, BMI, WHR and PA with cognitive scores at the 18-month followup interview using a cross-sectional design. Overall, the associations are in accord with Table 2. Age was significantly associated with all cognitive domains (all $P^{1}<0.01$ ). Compared with patients aged 50-59, older patients aged $\geq 60$ had significant lower scores in all cognitive domains (all Diff $<0$ and $P^{2}<0.01$ ), especially in attention (Diff (SE): -16.3 (1.4)). BMI was negatively associated with both delayed memory $\left(P^{1}=0.04\right)$ and attention $\left(P^{1}<0.001\right)$. WHR was negatively associated with immediate memory $\left(P^{1}=0.002\right)$, delayed memory $\left(P^{1}=0.002\right)$ and attention $\left(P^{1}=0.003\right)$. No significant association was found between PA and cognitive scores at the 18-month follow-up interview (all $P^{1}>0.05$ ). No substantial difference was observed in sensitivity analyses of the patients who underwent chemotherapy, nor after additional adjustment for comorbidities.

\section{DISCUSSION}

To the best of our knowledge, this is the first study to evaluate the associations of energy balance related factors (i.e. BMI, WHR and PA) and age with post-therapy cognitive recovery in $\mathrm{BC}$ survivors. We found that verbal fluency and attention improved in younger patients aged
$<60$ years and non-abdominally obese patients from 18 to 36 months after cancer diagnosis, but deteriorated among older patients aged $\geq 60$ years (i.e. verbal fluency and attention) and abdominally obese patients (i.e. verbal fluency); the deterioration in attention was more substantial than that in verbal fluency for older patients. Memory improved in all patients; however, compared with normal-weight patients, the improvement was significantly smaller in obese patients. Normal BMI indicated a small to moderate clinical significance on memory recovery, and normal WHR indicated a borderline small clinical significance on verbal fluency recovery. No significant association was found between PA and post-therapy cognitive recovery.

Our finding that the post-therapy cognitive recovery differed by age is consistent with biological theories of aging [11-13]. Normal aging in human leads to disproportionate structural changes in brain and variable degrees of cognitive decline in later life [13]. Although the relationship between brain atrophy and cognition decline needs to be continuously explored, structural imaging of the brain has recently provided an unprecedented view of age-related differences in structural brain measures and cognitive performance across a broad range of cognitive domains [14]. For example, executive functions involving attention, processing speed and inhibitory control, rely heavily, although not exclusively, on the frontal cortex. The volume and function of frontal cortex show three 
phases of atrophy. Its atrophy rate accelerates from age 20 to 40, slows down between 40 and 60, and accelerates again thereafter $[12,14]$. Moreover, memory formation depends on the hippocampus, which has a stable rate of atrophy until age 60, and the rate accelerates substantially with advancing age thereafter [14-16]. The opposite directions of longitudinal changes in verbal fluency and attention observed in patients aged $<60$ and $\geq 60$ are consistent with the pattern of frontal cortex atrophy. It is logical to suspect that patients aged $\geq 60$ were at an accelerated rate of frontal cortex atrophy, and their aging effect surpassed their recovery from therapy-induced cognitive impairment. The aging effect in patients aged $<60$ who were at a lower rate of frontal cortex atrophy, might not be large enough to counteract their post-therapy cognitive recovery. Further, older patients have lower cognitive reserve at pretreatment, which may be caused by underlying genetic factors as well as polypharmacy $[17,18]$. Therefore, they are likely to be more vulnerable to therapy-induced cognitive impairment. Future studies are needed to confirm our finding on the age-related discrepancy in post-therapy cognitive recovery.

Obesity is linked to cognitive impairment in the healthy elderly $[10,19]$. The underlying physiological mechanisms are complex and may involve several possibilities, including obesity-associated activation of innate immunity and structural brain change. Increased body mass index (BMI) is significantly related to shorter neuronal fiber bundle length and reduced brain volume, resulting in cognitive decline [20-24]. Recent evidence also suggests that WHR is independently associated with cognitive decline [25-27]. A cross-sectional study on central obesity and structural magnetic resonance imaging reported that greater WHR was associated with smaller hippocampi and more white matter hyperintensities after being adjusted for BMI and other risk factors [25]. Epidemiologic evidence linking obesity to cancer risk is convincing for several cancers, including postmenopausal breast cancer. Identified biological mechanisms that explain this link include hormonal alterations (eg, estrogen and leptin), induction of insulin-signaling pathways, activation of proinflammatory pathways, etc [28]. Furthermore, obesity appears to be a negative prognostic factor for recurrence and survival among both premenopausal and postmenopausal women with breast cancer [28]. However, some recent studies challenge this by demonstrating that overweight and early obese states are associated with improved survival, known as "obesity paradox" [29, 30]. It remains controversial whether the "obesity paradox" is a real association or an artificial association due to confounding and bias [30]. Our study found the post-therapy cognitive recovery in $\mathrm{BC}$ survivors also differed by obesity status. Normal-weight and overweight patients had the greatest improvements in memory. There is a profound implication of our finding that verbal fluency deteriorated in abdominally obese patients. Due to the novelty of our findings and the limitations of this study, further research, including intervention trials, is warranted to confirm the causal relationship between obesity and cognitive impairments.

Growing evidence suggests that exercise is related to better cognitive function in BC survivors [3135], however, the relationship may be dose-dependent (intensity and duration) in the elders [36]. Namely, a certain intensity of PA with a long duration (even years) is needed before cognitive changes can be observed [36]. While patients with moderate-intensity PA seemed to have the best cognitive performance at the 18-month follow-up interview and the greatest improvement in verbal fluency from the 18- to 36-month follow-up interview in our study, none of the associations was statistically significant after being corrected for multiple comparisons. It is worth noting that only $26.2 \%$ of our participants reported moderate and above intensity of PA at 6 months after diagnosis (data not shown), and this proportion doubled $(53.2 \%)$ at 18 months after diagnosis. It is most likely that our participants substantially decreased their PA intensity due to cancer treatments at 6 months after diagnosis, and then returned to their normal exercises over time. By the time we assessed their cognitive functions, the majority of our participants might not have engaged in moderate and above intensity PA long enough after their cancer treatments, so that the beneficial effects of PA could not reach statistical significance in our study. Taken together, the decreased PA intensity due to cancer treatments may explain the non-significant associations between PA and cognitive recovery. Moreover, our data show that PA intensity increased by 1.6 MET-hours/week, while BMI decreased by $0.17 \mathrm{~kg} / \mathrm{m}^{2}$ among our participants from 18 to 36 months after diagnosis (data not shown). Hence, exercise may have an indirect effect on cognitive change through modification of BMI or WHR. Future studies with a larger variation in PA and a longer duration of follow-up are warranted.

Strengths of this study include a population-based perspective longitudinal design and a large sample size. Furthermore, our findings regarding the association between normal WHR and verbal fluency recovery, as well as the association between normal BMI and memory recovery, indicated small to moderate clinical significance. A major limitation of this study is the absence of a cognitive assessment at the cessation of cancer therapy. The cognitive changes from the cessation of cancer therapy to 36 months after diagnosis should be more sizable than what we observed from 18 to 36 months after diagnosis. Therefore, the associations of age, BMI, WHR and PA with cognitive recovery and their clinical significance are probably underestimated in our study. Another limitation is that it was unclear whether our participants' weight changed after breast cancer diagnosis and/or therapy, and if so, towards what direction. This potential recent weight gain/ loss may have also affected 
the outcome but could not be accounted for.

In conclusion, this study examined the associations of age, BMI, WHR and PA with post-therapy cognitive recovery in $\mathrm{BC}$ survivors. We found that the post-therapy cognitive recovery differed by age and obesity status. Our findings indicate that obesity control may be beneficial for the post-therapy cognitive recovery in BC survivors. Further research, including intervention trials, is warranted to confirm the causal relationship between obesity and cognitive impairments.

\section{MATERIALS AND METHODS}

\section{Participants}

Participants of the current study came from the Shanghai Breast Cancer Survival Study (SBCSS), a large population-based cohort study of 5042 female $\mathrm{BC}$ survivors aged from 20 to 75 who were diagnosed with primary BC between March 2002 and April 2006 in Shanghai, China. The detailed method has been reported elsewhere [37]. In brief, a baseline survey utilizing a structured questionnaire covering demographic characteristics, anthropometry, cancer diagnosis, progression and treatment, PA and other lifestyle factors, was carried out at approximately 6 months after BC diagnosis. Three subsequent follow-up interviews were conducted at 18, 36, and 60 months after cancer diagnosis. Survival information of the participants who had lost contact in follow-up was also ascertained by regularly matching death certificates from the Shanghai Vital Statistics Registry against SBCSS database.

The Cognition Sub-study comprised two assessments of cognitive function that were integrated into the 18- and 36-month follow-up interviews of the SBCSS. When the Cognition Sub-study was initiated, two thirds of the SBCSS participants had completed their 18-month follow-up interviews. As a result, 1507 patients who were alive at the 18-month follow-up interview with a diagnosis between December 2004 and April 2006 were approached for the Cognition Sub-study. Among them, 15 were excluded due to a prior history of other cancers; 62 were excluded because of BC in situ; and 45 were excluded because of a prior history of stroke; leaving a total of 1385 BC survivors eligible for the Cognition Sub-study. Characteristics of eligible participants of the Cognition Sub-study and participants of the SBCSS were compared, and no difference was found in demographics, age at cancer diagnosis, and clinical features between these two study populations [4]. Among the eligible participants, 1286 completed the first cognitive assessment (participation rate: $92.9 \%$ ). Only 1143 patients were still alive at the 36-month follow-up interview and 1047 of them completed the second cognitive assessment (participation rate: $91.6 \%$ ). This study was approved by the Shanghai Municipal Center for Disease Control and Prevention Ethical Review Committee and Vanderbilt University Institutional Review Board. All participants provided written informed consent.

\section{Cognitive function assessments}

Participants' cognitive function was assessed by trained interviewers using a comprehensive battery of cognitive tests, including: (1) the Logical Memory Subtest of the Chinese Version of Wechsler Memory Scale to measure immediate memory and delayed memory [38]; (2) the Chinese Version of Category Fluency Test to measure verbal fluency [39]; and (3) the Chinese Version of the Stroop Test to measure attention [40]. The diagnostic validity of this battery of cognitive tests was previously evaluated in Shanghai. We found it was a sensitive battery to discriminate Alzheimer's disease and mild cognitive impairment from healthy controls [4]. All interviewers were formally trained by a neurologist from Hua Shan Hospital, Shanghai, China.

\section{Exposures}

Data on anthropometry and self-report PA collected in the SBCSS were used in the study. Participants' weight and self-report PA were collected at the 6- and 18-month follow-up interviews, whereas height, waist circumference and hip circumference were measured only at the 6-month follow-up interview. BMI was calculated by dividing the body weight (in kilograms) by the height (in meters) squared (weight/height ${ }^{2}$ ), and was further classified into four categories according to the obesity classification for Chinese, including underweight $\left(<18.5 \mathrm{~kg} / \mathrm{m}^{2}\right)$, normal $\left(18.5-23.9 \mathrm{~kg} / \mathrm{m}^{2}\right)$, overweight $\left(24.0-27.9 \mathrm{~kg} / \mathrm{m}^{2}\right)$ and obese $\left(\geq 28.0 \mathrm{~kg} / \mathrm{m}^{2}\right)$ [41]. WHR was calculated as waist measurement divided by hip measurement, and was further divided into three categories according to the cutoff points recommended by WHO (0.85) and studies in Asian populations $(0.80)$ for increased risk of metabolic complications, including normal $(<0.80), 0.80-0.84$ and abdominally obese $(\geq 0.85)$ [42]. Levels of PA were estimated using metabolic equivalent-hours per week (METs-hours/week), which expresses the intensity and energy expenditure of activities in a way comparable among persons of different weight [43]. 1 MET (1 kcal/ $\mathrm{kg} /$ hour) is roughly equivalent to the energy cost of sitting quietly at a metabolic rate of consuming $3.5 \mathrm{ml} \mathrm{O}^{2} / \mathrm{kg} /$ minute [44]. Intensity of PA was further divided into three categories according to the WHO recommendations on PA for adults, including light-intensity ( $<8.3$ MET-hours/ week), moderate-intensity (8.3-16.5 MET-hours/week), and vigorous-intensity ( $\geq 16.6$ MET-hours/week) [45]. 


\section{Statistical analysis}

Demographic variables and selected characteristics were compared between the subjects eligible for Cognition Sub-study and those who completed the study, using Student's $t$-test for continuous variables and Chi-square test for categorical variables. Linear regression models were used to examine the associations of age, BMI, WHR and PA with mean changes in cognitive scores of the period from 18- to 36-month follow-up interview (longitudinally), and with mean cognitive scores at 18-month follow-up interview (cross-sectionally). Bonferroni correction was used to control multiple comparisons. BMI and PA at 18-month follow-up interview were used in these analyses. Since waist and hip circumferences was not measured at 18-month follow-up interview, WHR at 6-month followup interview was used instead.

Linear regression analyses were adjusted for educational attainment, income, menopausal status, depression score, TNM stage, $\mathrm{BC}$ recurrence or diagnosis of other malignancies after the diagnosis of $\mathrm{BC}$, cancer treatments (including surgery, radiotherapy, chemotherapy and tamoxifen use), and time since the cessation of cancer therapy. To control regression to the mean, analyses of longitudinal changes in cognitive scores of the period from 18- to 36-month follow-up interviews were additionally adjusted for cognitive scores at 18-month follow-up interview. We also evaluated the clinically meaningful importance of the longitudinal changes in cognitive function using effect size (i.e. Cohen's $d$ : mean change in cognitive scores between two interviews divided by the standard deviation of cognitive score at the first interview) [46]. A Cohen's $d$ of 0.2 is considered a small effect, 0.5 a moderate effect, and 0.8 a large effect. Cohen's $d$ in the range of 0.2 to 0.3 is considered the minimally important difference for clinically meaningful effects [47]. Furthermore, we conducted sensitivity analyses limited to patients who underwent chemotherapy and additional analyses adjusted for comorbidities. All analyses were performed using SAS version 9.2 (SAS Institute, Cary, NC). Statistical significance was based on a two-sided probability with a significance level of 0.05 .

\section{CONFLICTS OF INTEREST} interests.

The authors declare that they have no competing

\section{GRANT SUPPORT}

This work was supported by the Department of Defense Breast Cancer Research Program (DAMD 1702-1-0607 to Xiao-Ou Shu), the National Cancer Institute (R01 CA118229 to Xiao-Ou Shu), the National Natural Science Foundation of China (81402734 to Pingping Bao), and the Shanghai Municipal Commission of Health and Family Planning (15GWZK0801 to Zhezhou Huang, PI: Fan Wu).

\section{REFERENCES}

1. Mandilaras V, Wan-Chow-Wah D, Monette J, Gaba F, Monette M, Alfonso L. The impact of cancer therapy on cognition in the elderly. Front Pharmacol. 2013 [cited 2015 May 5]; 4. doi: 10.3389/fphar.2013.00048.

2. O'Farrell E, MacKenzie J, Collins B. Clearing the air: a review of our current understanding of "chemo fog." Curr Oncol Rep. 2013; 15: 260-9. doi: 10.1007/s11912-0130307-7.

3. Ono M, Ogilvie JM, Wilson JS, Green HJ, Chambers SK, Ownsworth T, Shum DHK. A meta-analysis of cognitive impairment and decline associated with adjuvant chemotherapy in women with breast cancer. Neuro-Oncol. 2015; 5: 59. doi: 10.3389/fonc.2015.00059.

4. Zheng Y, Luo J, Bao P, Cai H, Hong Z, Ding D, Jackson JC, Shu X-O, Dai Q. Long-term cognitive function change among breast cancer survivors. Breast Cancer Res Treat. 2014; 146: 599-609. doi: 10.1007/s10549-014-3044-1.

5. Koppelmans V, Breteler MMB, Boogerd W, Seynaeve C, Schagen SB. Late effects of adjuvant chemotherapy for adult onset non-CNS cancer; cognitive impairment, brain structure and risk of dementia. Crit Rev Oncol Hematol. 2013; 88: 87-101. doi: 10.1016/j.critrevonc.2013.04.002.

6. Harada CN, Natelson Love MC, Triebel K. Normal Cognitive Aging. Clin Geriatr Med. 2013; 29: 737-52. doi: 10.1016/j.cger.2013.07.002.

7. Prickett C, Brennan L, Stolwyk R. Examining the relationship between obesity and cognitive function: A systematic literature review. Obes Res Clin Pract. 2015; 9: 93-113. doi: 10.1016/j.orcp.2014.05.001.

8. Sofi F, Valecchi D, Bacci D, Abbate R, Gensini GF, Casini A, Macchi C. Physical activity and risk of cognitive decline: a meta-analysis of prospective studies. J Intern Med. 2011; 269: 107-17. doi: 10.1111/j.1365-2796.2010.02281.x.

9. Spyridaki EC, Simos P, Avgoustinaki PD, Dermitzaki E, Venihaki M, Bardos AN, Margioris AN. The association between obesity and fluid intelligence impairment is mediated by chronic low-grade inflammation. Br J Nutr. 2014; 112: 1724-34. doi: 10.1017/S0007114514002207.

10. Łojko D, Pałys W, Czajkowska A, Wieczorowska-Tobis K, Łukasik S, Górna K, Sobieska M, Gajewska E, Suwalska A. Association of cognitive performance with the physical activity and body mass index in middle-aged and older rural inhabitants. Eur Rev Med Pharmacol Sci. 2014; 18: 3645 52.

11. Grady CL. Cognitive neuroscience of aging. Ann N Y Acad Sci. 2008; 1124: 127-44. doi: 10.1196/annals.1440.009.

12. Glisky EL. Changes in Cognitive Function in Human Aging. In: Riddle DR, editor. Brain Aging: Models, 
Methods, and Mechanisms. Boca Raton (FL): CRC Press; 2007 [cited 2015 May 11]. Available from http://www.ncbi. nlm.nih.gov/books/NBK3885/

13. Bishop NA, Lu T, Yankner BA. Neural mechanisms of ageing and cognitive decline. Nature. 2010; 464: 529-35. doi: 10.1038/nature08983.

14. Lockhart SN, DeCarli C. Structural imaging measures of brain aging. Neuropsychol Rev. 2014; 24: 271-89. doi: 10.1007/s11065-014-9268-3.

15. Dickerson BC, Sperling RA. Functional abnormalities of the medial temporal lobe memory system in mild cognitive impairment and Alzheimer's disease: insights from functional MRI studies. Neuropsychologia. 2008; 46: 162435. doi: 10.1016/j.neuropsychologia.2007.11.030.

16. Dickerson BC, Salat DH, Bates JF, Atiya M, Killiany RJ, Greve DN, Dale AM, Stern CE, Blacker D, Albert MS, Sperling RA. Medial temporal lobe function and structure in mild cognitive impairment. Ann Neurol. 2004; 56: 27-35. doi: 10.1002/ana.20163.

17. Loh KP, Janelsins MC, Mohile SG, Holmes HM, Hsu T, Inouye SK, Karuturi MS, Kimmick GG, Lichtman SM, Magnuson A, Whitehead MI, Wong ML, Ahles TA. Chemotherapy-related cognitive impairment in older patients with cancer. J Geriatr Oncol. 2016; 7: 270-80. doi: 10.1016/j.jgo.2016.04.008.

18. Ahles TA, Root JC, Ryan EL. Cancer- and Cancer Treatment-Associated Cognitive Change: An Update on the State of the Science. J Clin Oncol. 2012; 30: 3675-86. doi: 10.1200/JCO.2012.43.0116.

19. Dahl A. Body mass index, cognitive ability, and dementia: prospective associations and methodological issues in late life. Jönköping: Intellecta infolog; 2009 [cited 2015 Feb 10]. Available from http://hj.diva-portal.org/smash/get/ diva2:233987/FULLTEXT01.pdf

20. Cronk BB, Johnson DK, Burns JM. Body nass index and cognitive decline in mild cognitive impairment. Alzheimer Dis Assoc Disord. 2010; 24: 126-30. doi: 10.1097/ WAD.0b013e3181a6bf3f.

21. Bolzenius JD, Laidlaw DH, Cabeen RP, Conturo TE, McMichael AR, Lane EM, Heaps JM, Salminen LE, Baker LM, Scott SE, Cooley SA, Gunstad J, Paul RH. Brain structure and cognitive correlates of body mass index in healthy older adults. Behav Brain Res. 2014; 278C: 342-7. doi: 10.1016/j.bbr.2014.10.010.

22. Bolzenius JD, Laidlaw DH, Cabeen RP, Conturo TE, McMichael AR, Lane EM, Heaps JM, Salminen LE, Baker LM, Gunstad J, Paul RH. Impact of body mass index on neuronal fiber bundle lengths among healthy older adults. Brain Imaging Behav. 2013; 7: 300-6. doi: 10.1007/s11682013-9230-7.

23. Boyle CP, Raji CA, Erickson KI, Lopez OL, Becker JT, Gach HM, Longstreth WT, Teverovskiy L, Kuller LH, Carmichael OT, Thompson PM. Physical activity, body mass index, and brain atrophy in Alzheimer's disease.
Neurobiol Aging. 2015; 36 Suppl 1: S194-202. doi: 10.1016/j.neurobiolaging.2014.05.036.

24. Ryan L, Walther K. White matter integrity in older females is altered by increased body fat. Obes Silver Spring Md. 2014; 22: 2039-46. doi: 10.1002/oby.20815.

25. Jagust W, Harvey D, Mungas D, Haan M. Central obesity and the aging brain. Arch Neurol. 2005; 62: 1545-8. doi: 10.1001/archneur.62.10.1545.

26. Kerwin DR, Gaussoin SA, Chlebowski RT, Kuller LH, Vitolins M, Coker LH, Kotchen JM, Nicklas BJ, Wassertheil-Smoller S, Hoffmann RG, Espeland MA, Women's Health Initiative Memory Study. Interaction between body mass index and central adiposity and risk of incident cognitive impairment and dementia: results from the Women's Health Initiative Memory Study. J Am Geriatr Soc. 2011; 59: 107-12. doi: 10.1111/j.15325415.2010.03219.x.

27. Ma L, Feng M, Qian Y, Yang W, Liu J, Han R, Zhu H, Li Y. Insulin Resistance Is an Important Risk Factor for Cognitive Impairment in Elderly Patients with Primary Hypertension. Yonsei Med J. 2015; 56: 89. doi: 10.3349/ ymj.2015.56.1.89.

28. Byers T, Sedjo RL. Body fatness as a cause of cancer: epidemiologic clues to biologic mechanisms. Endocr Relat Cancer. 2015; 22: R125-34. doi: 10.1530/ERC-14-0580.

29. Xu X, Zhou L, Miao R, Chen W, Zhou Y, Pang Q, Qu K, Liu C. Association of cancer mortality with postdiagnosis overweight and obesity using body mass index. Oncotarget. 2016; 7: 5023-9. doi: 10.18632/oncotarget.6517.

30. Lennon H, Sperrin M, Badrick E, Renehan AG. The Obesity Paradox in Cancer: a Review. Curr Oncol Rep. 2016; 18: 56. doi: 10.1007/s11912-016-0539-4.

31. Chan RJ, McCarthy AL, Devenish J, Sullivan KA, Chan A. Systematic review of pharmacologic and nonpharmacologic interventions to manage cognitive alterations after chemotherapy for breast cancer. Eur J Cancer Oxf Engl 1990. 2015; 51: 437-50. doi: 10.1016/j.ejca.2014.12.017.

32. Pakiz B, Flatt SW, Bardwell WA, Rock CL, Mills PJ. Effects of a Weight Loss Intervention on Body Mass, Fitness, and Inflammatory Biomarkers in Overweight or Obese Breast Cancer Survivors. Int J Behav Med. 2011; 18: 333-41. doi: 10.1007/s12529-010-9079-8.

33. Marinac CR, Godbole S, Kerr J, Natarajan L, Patterson RE, Hartman SJ. Objectively measured physical activity and cognitive functioning in breast cancer survivors. J Cancer Surviv Res Pract. 2014; . doi: 10.1007/s11764-014-0404-0.

34. Potential factors associated with perceived cognitive impairment in breast cancer survivors - Springer. [cited 2015 May 11]; . doi: 10.1007/s00520-015-2708-7.

35. Myers JS. Chemotherapy-related cognitive impairment: the breast cancer experience. Oncol Nurs Forum. 2012; 39: E31-40. doi: 10.1188/12.ONF.E31-E40.

36. Kirk-Sanchez NJ, McGough EL. Physical exercise and cognitive performance in the elderly: current perspectives. 
Clin Interv Aging. 2013; 9: 51-62. doi: 10.2147/CIA. S39506.

37. Shu XO, Zheng Y, Cai H, Gu K, Chen Z, Zheng W, Lu W. Soy Food Intake and Breast Cancer Survival. JAMA J Am Med Assoc. 2009; 302: 2437-43. doi: 10.1001/ jama.2009.1783.

38. Salmon DP, Jin H, Zhang M, Grant I, Yu E. Neuropsychological assessment of chinese elderly in the Shanghai dementia survey. Clin Neuropsychol. 1995; 9: 159-68. doi: 10.1080/13854049508401598.

39. Chan AS, Poon MW. Performance of 7- to 95-year-old individuals in a Chinese version of the category fluency test. J Int Neuropsychol Soc JINS. 1999; 5: 525-33.

40. Lee TM, Chan CC. Stroop interference in Chinese and English. J Clin Exp Neuropsychol. 2000; 22: 465-71. doi: 10.1076/1380-3395(200008)22:4;1-0;FT465.

41. Chen C, Lu FC, Department of Disease Control Ministry of Health, PR China. The guidelines for prevention and control of overweight and obesity in Chinese adults. Biomed Environ Sci BES. 2004; 17 Suppl: 1-36.

42. World Health Organization. Waist circumference and waisthip ratio. Geneva; 2011 [cited 2015 May 13]. Available from http://www.who.int/nutrition/publications/obesity/ WHO_report_waistcircumference_and_waisthip_ratio/en/
43. Ainsworth BE, Haskell WL, Leon AS, Jacobs DR, Montoye HJ, Sallis JF, Paffenbarger RS. Compendium of physical activities: classification of energy costs of human physical activities. Med Sci Sports Exerc. 1993; 25: 71-80.

44. Ainsworth BE, Haskell WL, Herrmann SD, Meckes N, Bassett DR, Tudor-Locke C, Greer JL, Vezina J, WhittGlover MC, Leon AS. 2011 Compendium of Physical Activities: a second update of codes and MET values. Med Sci Sports Exerc. 2011; 43: 1575-81. doi: 10.1249/ MSS.0b013e31821ece12.

45. World Health Organization. Global Recommendations on Physical Activity for Health. 2010 [cited 2015 May 13]. 58 p. Available from http://www.who.int/dietphysicalactivity/ publications/9789241599979/en/

46. Cohen J. Statistical Power Analysis for the Behavioral Sciences (2nd Edition). Hillsdale, New Jersey: Lawrence Earlbaum Associates; 1988.

47. Revicki DA, Cella D, Hays RD, Sloan JA, Lenderking WR, Aaronson NK. Responsiveness and minimal important differences for patient reported outcomes. Health Qual Life Outcomes. 2006; 4: 70. doi: 10.1186/1477-7525-4-70. 